\title{
Añagazas de la fachada ventilada: ¿pluvial o revestida?
}

\section{Ignacio Paricio y Cristina Pardal}

ace veinte años importamos el Cavity Wall, un "rain screen" anglosajon, en vez de actualizar nuestro tabique
pluvial. Lo peor es que la adoptamos como fachada venPero poco a poco olvidamos las exigencias de la cámara como pantalla (screen) corta aguas. Cada vez somos menos rigurosos con su eficacia en el diseño de las fijaciones. Mientras tanto aligeramos y debilitamos la hoja interior que deja de ser tampón yarantia final. A los más preocupados esa probable ineficacia les lleva a proyectar hojas interiores estancas con lo que la hoja exterior es una pura herramienta compositiva. Vestiditos de munecas. Quizás tampoco está tan mal.

Les dejo con Cristina Pardal que ha ordenado nuestras op niones sobre el tema.

El sistema de fachada de doble hoja limitando una cámara drenante - "Rain Screen" - , originario del norte de Europa, se introdujo en nuestro país, como en otros países del Mediterráneo, adoptando un nombre - Fachada Ventilada - que genera cierta confusión en cuanto al funcionamiento primigenio del sistema. En origen, este tipo de fachada tiene como objetivo crear una cámara drenante que garantice la estanqueidad en unos sistemas de fachada que tradicionalmente estaban construidos con materiales porosos - fábrica de ladrillo - y que para determinagaua en climas donde la lluvia es muy persistente.

En España, a pesar de existir una interesantísima tradición de tabiques pluviales para resolver las medianeras - lo que sería la traducción prácticamente literal de "Rain Screen" -, importamos este sistema de fachada de doble hoja rebautizándolo con el nombre de Fachada Ventilada. No se trata da una mera cuestion linguilstica. Con este cambio se pone de manifiesto el meno nterés por los problemas de estanquidad para dar relevancia comportamiento termico de este sistema de fachada. La doble disipando el exceso de calor que haya podido sobrecalentar la hoja exterior. Este movimiento del aire puede representar una mejora en el comportamiento térmico de la fachada en verano. Es decir que si la hoja exterior originaria se podía asimilar a paraguas del edificio, en nuestro clima este paraguas ha sido entendido por muchos arquitectos como una sombrilla.

Pero lo que realmente hay en el fondo de todo este proceso, está apropiación por parte de nuestra arquitectura del sistema de fachada de doble hoja con cámara drenada, es una cuestión puramente compositiva. Ya sea paraguas o sombrilla, la hoja exterior formada por placas colgadas permite vestir el edificio como si de un juego de "vestiditos de muñecas recortables de papel" se tratara. El "vestido" es independiente del sistema porante del edificio o del subsistema estructural de fachada; ancla a éste con mecanismos de fijación en seco de carácter reversible; las placas son independientes entre ellas; la junta abierta permite despreocuparse de los encuentros entre piezas; etc. La libertad compositiva que permite este tipo de fachada es incuestionable y resulta un gran atractivo para los arquitectos.

Estanqueidad, confort térmico, imagen; todos ellos son objetivos deseables. El problema surge cuando el arquitecto confunde estos objetivos y adopta una solución constructiva inadecuada o de la que desconoce el comportamiento. Si los objetivos no están claros, no lo están las leyes que deben orientar el diseño de la fachadas de doble hoja donde la interior es perfectamente estancochác de doble hoja donde la interior es perfectamente estanenergético de la fachada? Qué pocos arquitectos se hacen estas preguntas cuando proyectan una "fachada ventilada" y cuántos de ellos buscan una respuesta que les permita optimizar el diseño. De la cámara teórica que enuncian los textos de construcción a la que en muchas ocasiones se termina construyendo existen diferencias tales que hacen que se pierda el sentido del sistema. El cómputo entre la superficie construida y la útil estrecha las cámaras hasta espesores anecdóticos. Estos espacios angostos se trufan de mecanismos de fijación teniendo poco o ningún cuidado en asegurar un corte en el avance del agua por tensión superficial. La geometría irregular de la cámara tampoco permite garantizan el flujo laminar ascendente del aire limitando su posible movimiento a erráticas turbulencias.

La fachada ventilada ha llegado a un punto en el que aparentemente "todo vale". Recuperar la esencia del sistema no se puede hacer negando los nuevos objetivos que la arquitectura ha encomendado a la fachada de doble hoja. Debemos dejar de englobar dentro de un mismo término, el de fachada ventilada, soluciones que en realidad tienen objetivos diversos: garantiza la estanqueidad, mejorar el confort térmico, dar una determnada imagen al edificio.

La fachada drenada (rain screen) es aquella que resuelve la estanno está provista de capas impermeables. En este tipo de fachada se debe tener especial cuidado en evitar que el agua pase de hoja exterior a la interior, cosa que supondría el fallo del sistema: dimensionado de las juntas de la hoja exterior, dimensionado de ancho de la cámara, diseño de los sistemas de fijación, diseño de los mecanismos de expulsion del agua hacia el exterior. equipo de arquitectos B720 convierte las fachadas del edificio donde se sitúa su estudio en la calle Josep Tarradellas on un sistema de doble hoja al añadir sobre el cerramiento cerámico imagen renovada al edificio a la vez que oculta el aislamiento térmico que disponen sobre la antigua fachada. Pero el objetivo principal de la intervención es el de mejorar los problemas de estanquidad que sufría el edificio a causa del inevitable deterioro a lo largo de los años.

La fachada ventilada (ventilated façade) es aquella que confía en una cierta circulación de aire por la cámara para mejorar el confort térmico en el espacio interior en climas calurosos. De la misma manera que en el caso del la fachada drenada su corecto comportamiento debe estar garantizado para evitar entradas de agua en el edificio; en el caso de la fachada ventilada, esgrimir este objetivo como justificante del sistema implica que su eficacia debe ser demostrable y no simplemente supuesta. Deberemos conocer el caudal de aire, su velocidad de desplazamiento, la energía en forma de calor que es capaz de disipar quión en la temperatura del espacio interior. SUMO Arquitectos proyectan para el Equipamiento Multifuncional de la

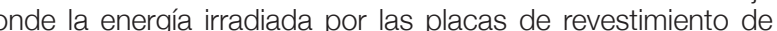
aluminio lacado en color negro es disipada por convección gracias a la cámara de $50 \mathrm{~mm}$ de ancho sin ningún elemento que obstaculice la circulación del aire en vertical. En este caso la hoja interior es perfectamente estanca ya que está formada por paneles sándwich con junta machihembrada y sellada.

La fachada revestida (veneer façade). Recurrir a una fachada de doble hoja con la simple voluntad de vestir el edificio con la imagen deseada es perfectamente lícito. Como escribía Vitrubio los valores de la Arquitectura son tanto la utilidad y la solidez como la belleza. No entraremos aquí a discutir si a este revestimiento, la belleza. No entraremos aqui a discutir si a este revestimiento, otras funciones de cara a la eficiencia y optimización de los materiales y sistemas; forma parte de otro discurso. Lo que sí está claro es que la función estetica justifica un tipo de fachada distinto a la drenada y la estanca. En este caso la cámara puede ser prácticamente inexistente ya que de lo que se trata es simplemente de fijar mecánicamente, en lugar de adherir, un determinado revestimiento. La "cámara" es el espacio que resulta de disponer los mecanismos de anclaje. Este tipo de fachadas está ampliamente justificado cuando de lo que se trata es de adelgazar la fachada. Un claro ejemplo de fachada revestida y de poco espesor es la del edificio para Carburos Metálicos en la calle Aragón de Barcelona. Los arquitectos Amadó y Domènech expresan este papel de simple aplacado de la hoja exterior al pasar la piedra por delante del marco fijo de la carpintería de madera dejando abierta la junta entre ambos y, por lo tanto, expuesta a la entrada directa del agua acumulada sobre el alfeizar. El escaso espesor de la cámara hace prácticamente inviable la ventilación. Tampoco es necesaria. El color claro de la piedra evita el excesivo sobrecalentamiento de la única fachada muy expuesta, la noroeste.

Para cerrar este artículo queremos hacer hincapié en la importancia de definir claramente cuáles son las funciones que debe satisfacer el conjunto camara - hoja exterior y, en base a ellas, diseñar la mejor solución.

La falta de conocimiento del sistema por parte del arquitecto se evidencia tanto en los errores de diseño que ocasionan fallos graves de funcionamiento como en el poco eficiente sobredimensionado de los mecanismos que aportan estanquidad y control térmico. Si en el primer caso se peca de un exceso de confianza y falta de rigor, en el segundo es precisamente la desconfianza la que lleva a implementar el sistema con elementos innecesarios que lo encarecen.

La actual proliferación de fachadas revestidas es consecuencia de esta falta de confianza en el sistema planteado. Es habitual ver como a la hoja interior se le acaba encomendando la resolución de las envolventes estanca y termica simplemente ante la duda de si el drenaje de la cámara será efectivo y la ventilación suficiente. De esta manera la cámara pierde todo su sentido a la vez que la hoja exterior pasa a ser un simple acabado de fachada.

ABSTRACT. El sistema de fachada de doble hoja, lo que en los países anglosajones se conoce como "rain screen", se ha importado a nuestro pais adoptando el nombre de "fachada ventilada". Quizas porque se ha saciones en la cámara podría beneficiar el confort de verano en nuestro clima. Esa insistencia en la ventilación ha propiciado una seria confusión en cuanto al papel de la cámara. Su misión original era impedir el paso del agua pero su exito, por la libertad del acabado exterior, está diluyendo esa función. Como consecuencia muchas veces no se garantiza a imposibilidad del paso del aqua hacia el interior.

Estas notas pretenden poner de manifiesto que lo que hoy conocemos como "fachada ventilada" incluye soluciones de cerramientos de doble denar esta realidad, plantea distinguir entre fachada drenada, fachada ventilada y fachada revestida.

Ignacio Paricio es doctor arquitecto por la UPC y Catedrático del Departamento de Construcciones Arquitectonicas de la UPC.

Cristina Pardal es doctor arquitecto por la UPC y profesora adscrita al Departamento de Construcciones Arquitectonicas I de la UPC.
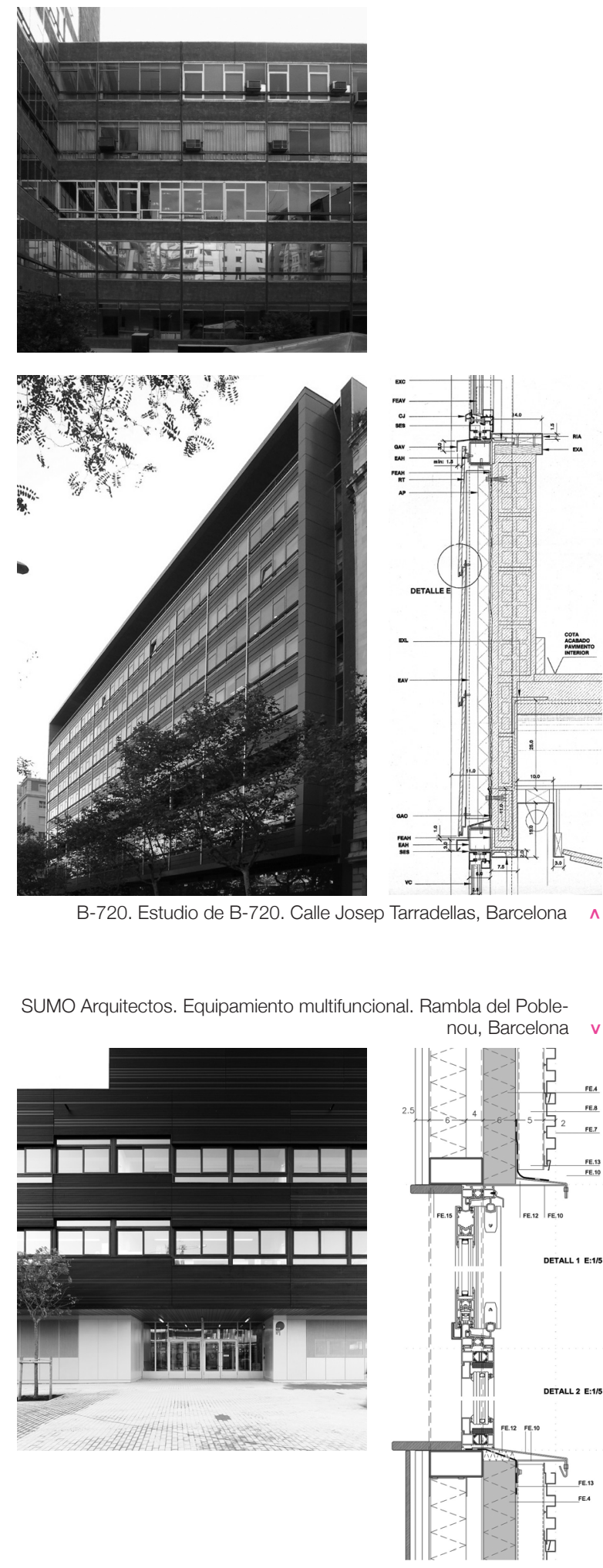

Lluís Domènech y Roser Amadó. Edificio para Carburos Metálicos,
Calle Aragó, Barcelon
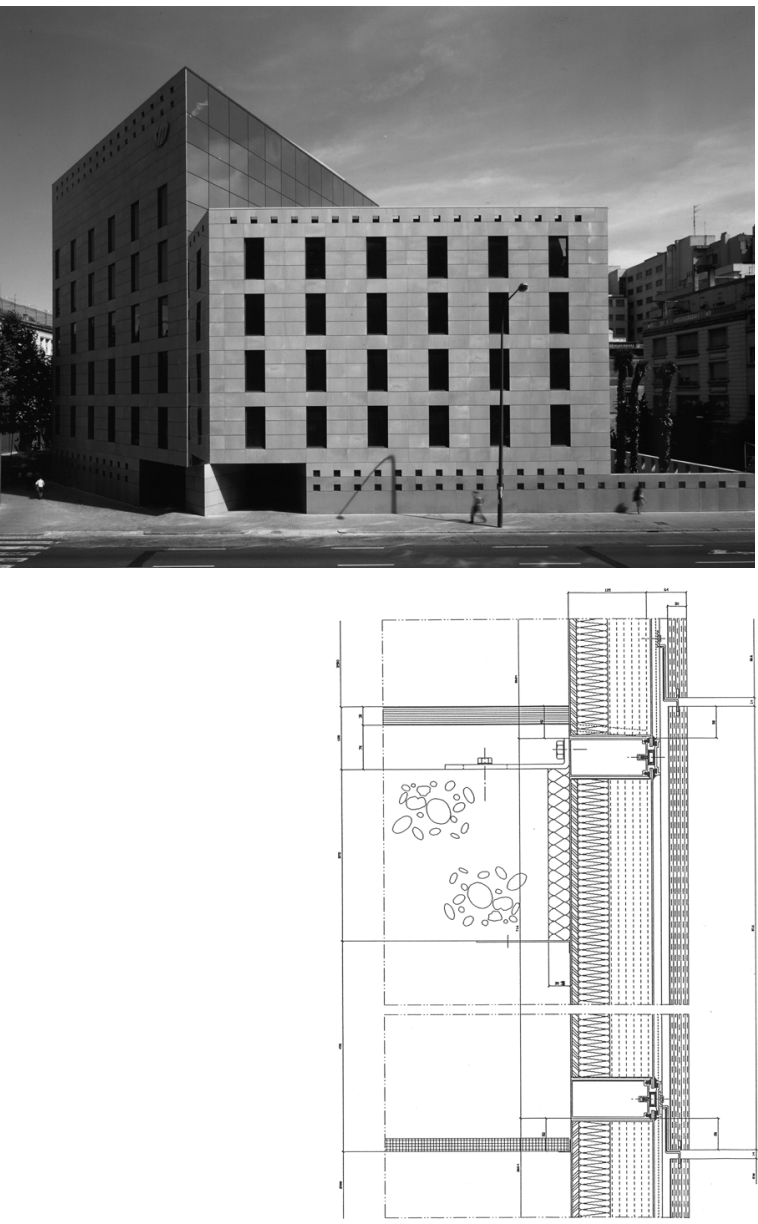